\title{
Cytogenetic and anatomic behavior of cytochimeras and total polyploids in cassava
}

\author{
D.Y. Hashimoto-Freitas ${ }^{1}$ and N.M.A. Nassar $^{2}$ \\ ${ }^{1}$ Programa de Pós-Graduação em Botânica, Universidade de Brasília, \\ Brasília, DF, Brasil \\ ${ }^{2}$ Departamento de Genética e Morfologia, Universidade de Brasília, \\ Brasília, DF, Brasil \\ Corresponding author: N.M.A. Nassar \\ E-mail: nagibnassar@geneconserve.pro.br
}

Genet. Mol. Res. 12 (4): 4879-4894 (2013)

Received August 8, 2013

Accepted September 4, 2013

Published October 22, 2013

DOI http://dx.doi.org/10.4238/2013.October.22.7

\begin{abstract}
Cassava periclinal cytochimeras, cultivars, and interspecific hybrid and polyploid types were studied in relation to embryonic, cytogenetic, and anatomical behavior. Their apical shoots, pollen grains, male and female buds, roots, stomata, and flowering period were analyzed. Chimeras exhibited increased size of L1 and L2 cells. Polyploidy led to enlargement of stomata in chimeras whereas L2 gave tetraploid chromosome configurations, tetrad irregularity, decrease of pollen viability, and increase in frequency of polyembryo sacs. The chimeric composition of tetraploids L1 and L2 and diploid L3 expressed a notable epigenetic effect seen in a marked enlargement of edible roots compared to total diploid. One of the chimeric types was accompanied by complete flowering inhibition. Pollen viability and diameter appeared to be reliable markers to determine ploidy levels.
\end{abstract}

Key words: Apical meristems; Apomixis; Epigenetic; Pollen viability; Root productivity 


\section{INTRODUCTION}

Manihot is a genus with 100 known species (FAO, 2013). All species investigated have a chromosome number of $2 \mathrm{n}=36$, including the cultivated species Manihot esculenta Crantz (Nassar, 1978; De Carvalho and Guerra, 2002). Polyploidy has played an important role in developing cultivated species and has been successfully used in breeding productive cultivars (Sreekumari et al., 2000; Ceballos et al., 2004; Nassar and Ortiz, 2008).

In vegetatively propagated plants, as in the case of cassava, induced polyploids can be obtained by colchicine treatment of lateral buds followed by vegetative propagation (Nassar, 2003). However, chimeras may frequently arise in this case as a result of incomplete penetration of colchicine to the third layer (Nassar, 2003). It may initially form a sectorial chimera, which soon turns into a periclinal one due to the process of substitution (Marcotrigiano and Bernatzky, 1995). The stable form is usually the periclinal one, and it can be identified by examining tissues derived from layers L1, L2, and L3 (Burge et al., 2002). The first one forms the epidermis, the second gives rise to gametes and the third forms vascular cylinders including pericycle, which is responsible for root formation (Zhu et al., 2007).

Polyploid cassava has been shown to be productive (Hahn et al., 1990; Gomes and Nassar, 2013); however, no reference to cytochimeras and their role in productivity is available. Polyploidy has also been cited in relation to polyembryonic formation and apomixis occurrence in cassava (Freitas and Nassar, 2013). We tried to determine in this study the limit and potential of polyploidization in inducing alterations in polyembryony and consequently apomixis rate. There are few studies in the literature on cytochimeras in root crops, and far less with regard to cassava. Inasmuch as we know, this is the first report on this subject.

\section{MATERIAL AND METHODS}

\section{Plant material}

Four cultivars and an interspecific hybrid of cassava, besides a progeny of a polyploidized type, were used in this experiment. A brief description of them is shown as follows.

- UnB 530. An indigenous cultivar, erect shrub, ca. 1-1.5 m tall. Prominent petiole scars, ca. $1 \mathrm{~cm}$. Greenish red young stems, petioles, buds, and fruits. Winged ovary. Cylindrical roots.

- UnB 530p. Polyploidized artificially with colchicine and vegetatively propagated UnB 530 stem, by colchicine application on lateral buds (Nassar, 2003). Erect to semi-decumbent shrub, ca. 0.5-2 m tall. Prominent petiole scars, ca. $1 \mathrm{~cm}$. Greenish red young stems, petioles, buds, and fruits. Winged ovary. Cylindrical roots (Nassar et al., 2012).

- UnB 530p progeny. Progeny obtained from open pollination of UnB 530p, constituting 37 individuals designated 530-1 to 530-37.

- UnB 530-5. Triploid individual from UnB 530p progeny. Erect to semi-decumbent shrub, ca. 1-1.5 m tall. Dichotomous branches, erect to semi-decumbent. Greenish red young stems, petioles, buds, and fruits. Winged ovary. Cylindrical roots.

- UnB 530-19. Triploid individual from UnB 530p progeny. Erect to semi-decumbent shrub, ca. 1-2.5 m tall. Dichotomous branches, erect to semi-decumbent. Red-greenish young stems, petioles, buds, and fruits. Winged ovary. Cylindrical roots.

- UnB 307-1. Cassava cultivar. Erect to semi-decumbent shrub, ca. 1-2 m tall. Prominent 
petiole scars, ca. $0.8 \mathrm{~cm}$. Greenish stems, petioles, buds, and fruits with mottled purple. Slightly winged ovary. Cylindrical roots, ca. $30-80 \mathrm{~cm}$ long, $2-30 \mathrm{~cm}$ in diameter.

- UnB 307-1 poly. Polyploidized artificially with colchicine and vegetatively propagated UnB 307-1 (Nassar, 2003). Erect to semi-decumbent shrubs, ca. $2 \mathrm{~m}$ tall. Prominent petiole scars, ca. $1 \mathrm{~cm}$. Greenish stems and petioles with mottled purple. Cylindrical roots, ca. 10-80 cm long, 2-35 cm in diameter. Called Chimera 307-1.

- Manihot glaziovii x M. esculenta. Hybrid produced sexually (Nassar, 2003). Erect shrub, ca. $2.5 \mathrm{~m}$ tall. Greenish non-prominent petiole scars. Stem, leaves, buds, and fruits with some red spots. Fruit slightly winged. Fibrous roots. Called Glaz hybrid.

- M. glaziovii x M. esculenta poly. Polyploidized artificially with colchicine and vegetatively propagated M. glaziovii x M. esculenta (Nassar, 2003). Erect shrub, ca. $3 \mathrm{~m}$ tall. Non-prominent petiole scars. Greenish stem, leaves, buds, and fruits with some red spots. Fruit with no prominent wing. Fibrous roots. Called Chimera glaz.

All these plants are propagated and established at the Living Collection of Manihot with the Experimental Station of Universidade de Brasília, Brasília, DF, Brazil.

\section{Apical shoot anatomy}

Apical shoots of UnB 530, UnB 530p, 307-1, Chimera 307-1, Glaz hybrid, and Chimera glaz were collected and fixed in Carnoy for 14 days. They were dehydrated and embedded in paraffin (Kraus and Arduin, 1997), double-stained, and mounted in resin (Paiva et al., 2006). Longitudinal cross-sections of $6 \mu \mathrm{m}$ were made on rotary Leica microtome RM 2145. Two sections of each plant had 20 height cells measured within each L1, L2, and L3 layers. The Tukey test was used to determine statistical differences at $\mathrm{P} \leq 5$ to compare cell size within samples.

\section{Stomatal morphology, size, and density}

Dried leaves of $1 \mathrm{~cm}^{2}$ UnB 530, UnB 530p, 530-5, 530-19, 307-1, Chimera 307-1, Glaz hybrid, and Chimera glaz were gold coated in a Leica EM SCD 500 metalyzer, and photographed in a JEOL JSM 700 1-F scanning electron microscope for morphological observations. For measurements, 5 leaves at the fourth internode of the samples cited had their abaxial surface at median lobe next to main vein covered by two layers of glaze (Kraus and Arduin, 1997). These prints were laid up on a slide with water, and a total of 9 photographs were taken with a 40X lens. Stomatal size was considered to be the length from the outer margins of guard cells. Density was calculated for an area of $1 \mathrm{~mm}^{2}$. The Tukey test was used to determine statistical differences at $\mathrm{P} \leq 0.05$.

\section{Fertility and pollen morphology}

Plant fertility was measured by pollen viability and formed seeds. Ovule number per ovary at early stages of development to mature seeds inside fruits was determined, and the ratio ovule/ovary (for immature seed) and seed/fruit (for mature seed) were considered. Flowering period was recorded for all cited plants from March 2009 to April 2013.

For pollen viability and microspore investigation, male buds were collected, fixed in Carnoy, preserved in $70 \%$ ethanol and stained in $2 \%$ acetocarmine (Nassar, 2003). UnB 530, UnB 530p, 530-5, 530-19, 530-36, 307-1, Chimera 307-1, Glaz hybrid, and Chimera glaz were analyzed for presence of dyad, triad, or polyad spores (Nassar, 2003), with or without micronuclei. 


\section{Meiotic and mitotic analyses}

For meiotic study, male buds with 1-3 $\mathrm{mm}$ in length were kept in aquose solution of $0.02 \mathrm{M}$ colchicine and glycerin for $6 \mathrm{~h}$. They were then collected and fixed in Carnoy for 14 days, then preserved in $70 \%$ ethanol. Staining was done with $2 \%$ acetocarmine (Nassar, 2003). Chromosome associations were classified as univalent, bivalent, trivalent, or tetravalent, and their averages from 10 metaphase I cells were calculated as simple mean.

For mitotic study, root tips were pretreated with $0.002 \mathrm{M} 8$-hydroxyquinoline for $24 \mathrm{~h}$, fixed in Carnoy and kept in $70 \%$ ethanol. Slides were prepared by submerging them in $5 \mathrm{~N} \mathrm{HCl}$ for $10 \mathrm{~min}$ and staining for $2 \mathrm{~h}$ with Schiff's reagent (Kraus and Arduin, 1997), followed by $2 \%$ acetocarmine (Nassar, 2003). Chromosome number was determined in a minimum of 10 metaphase cells.

\section{Embryo sac anatomy}

Mature embryo sacs of all flowering plants within this study were analyzed by the clearing technique (Young et al., 1979) in interferential contrast microscopy. Ovules with only one sac were classified as of sexual origin; ovules with more than one sac were considered polyembryonic.

\section{Root productivity}

Edible root formation of cultivars UnB 530, UnB 530p, and 530-19 were numbered and roots were weighed. Leica DM 2500 and Zeiss Axioscop 2 light microscopes were used for observations. Leica Application Suite 4.0 or the Photoshop CS4 software was used for image capture and edition. Measures were taken with Image Pro Plus version 4.5.0.29, and Assistant Beta version 7.6 was used for statistical tests.

\section{RESULTS}

\section{Apical shoot anatomy}

Sections revealed well-defined layers in apical shoots (Figure 1). All layers showed anticlinal and periclinal divisions. The Tukey test at $\mathrm{P} \leq 0.05$ showed significant differences within samples (Table 1). Comparing averages of cell heights (or cell sizes) between diploid and chimera samples, an increase in L1 and L2 was observed between the pairs UnB 530 and UnB 530p, 307-1 and Chimera 307-1, and Glaz hybrid and Chimera glaz. Layer L3 showed no statistical difference between all samples analyzed.

\section{Stomata in chimeras compared to diploids and triploids}

Paracytic stomata were seen in all samples (Figure 2). Average of stomatal length and density at $\mathrm{P} \leq 0.05$ showed differences between samples (Figure 3 ). UnB 530p was bigger in size than UnB 530, and resembled 530-5; 530-19 had an intermediate length of stomata. Chimera glaz showed the highest average within the samples examined, almost 6 times bigger than Glaz hybrid. Density of stomata did not follow a pattern in relation to increase or decrease in ploidy level in UnB 530 samples; however, for the chimeras, density decreased with a rise in ploidy layer. 


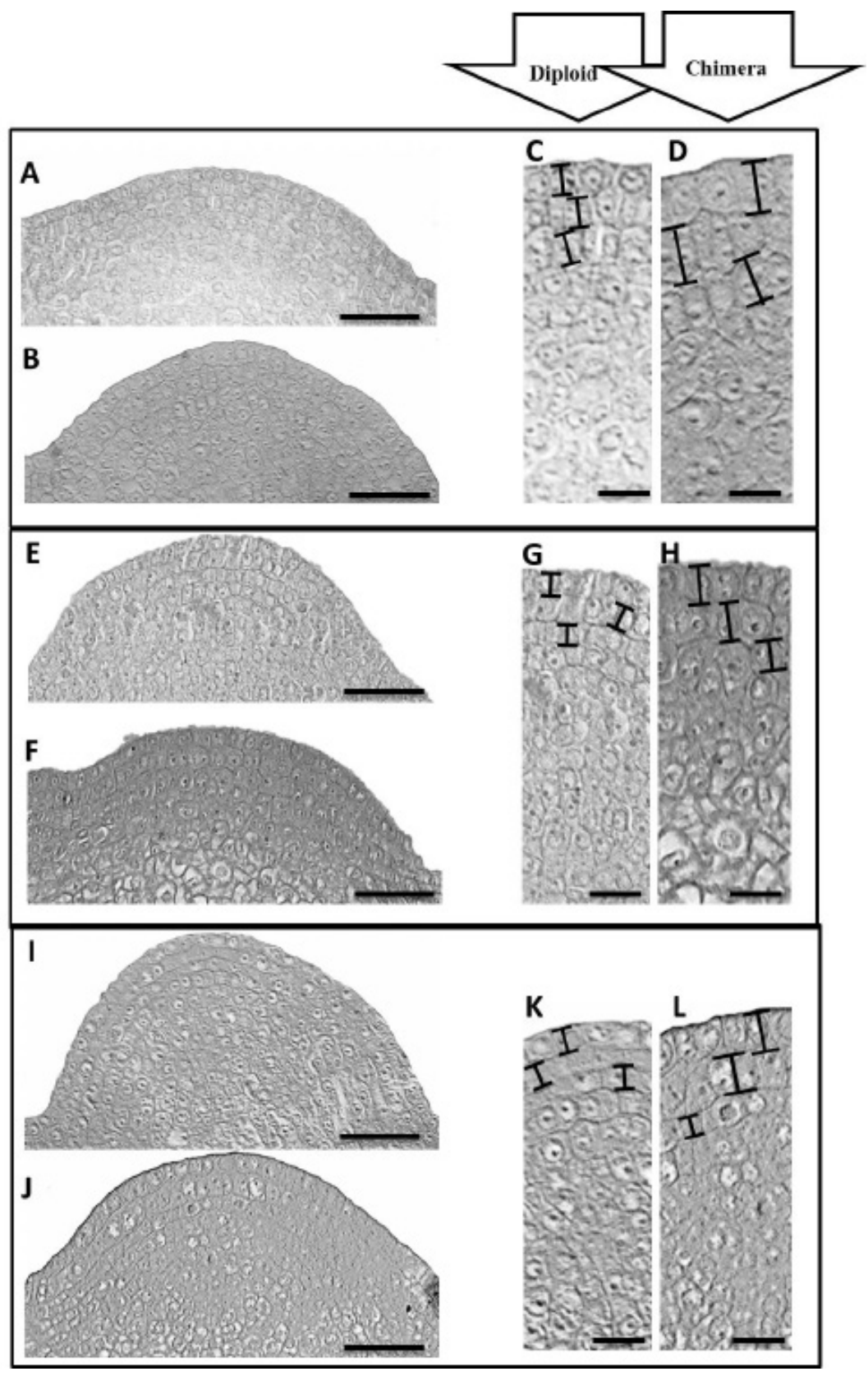

Figure 1. Apical shoot sections of diploid (UnB 530, 307-1, and Glaz hybrid) and chimeric cassava (UnB 530p, Chimera 307-1, and Chimera glaz) showing L1, L2, and L3 layers. A. UnB 530. B. UnB 530p. C. Detail of UnB 530, note certain resemblance of height cells within layers. D. Detail of UnB 530p. Note resemblance in L1 and L2 cell sizes. E. 307-1. F. Chimera 307-1. G. Detail of 307-1. H. Detail of chimera 307-1. Note L1 and L2 layers bigger than L3. I. Glaz hybrid. J. Chimera glaz. K. Detail of Glaz hybrid. L. Detail of Chimera glaz. Note L1 and L2 layers bigger than L3. Bar $=30 \mu \mathrm{m}$ (A. B. E. F. I. J.); $20 \mu \mathrm{m}$ (C. D. G. H. K. L.). 
Table 1. Averages of 20 cells of two apical shoot meristems per plant of diploid (UnB 530, 307-1, and Glaz hybrid) and chimeric cassava (UnB 530p, Chimera 307-1, and Chimera glaz) represented in L1, L2, and L3 layers (in micrometers).

\begin{tabular}{lrrr}
\hline Sample & L1 & L2 & L3 \\
\hline UnB 530 & $13.4^{\mathrm{b}}$ & $11.6^{\mathrm{c}}$ & $13.3^{\mathrm{a}}$ \\
UnB 530p & $16.4^{\mathrm{a}}$ & $16.7^{\mathrm{b}}$ & $14.1^{\mathrm{a}}$ \\
307-1 & $7.8^{\mathrm{d}}$ & $8.5^{\mathrm{d}}$ & $8.1^{\mathrm{d}}$ \\
Chimera 307-1 & $12.1^{\mathrm{c}}$ & $12.6^{\mathrm{c}}$ & $7.8^{\mathrm{d}}$ \\
Glaz hybrid & $11.9^{\mathrm{c}}$ & $11.7^{\mathrm{c}}$ & $10.8^{\mathrm{c}}$ \\
Chimera hybrid & $17.2^{\mathrm{a}}$ & $18.4^{\mathrm{a}}$ & $11.5^{\mathrm{c}}$ \\
\hline
\end{tabular}

Same superscript letters indicate no statistical difference.
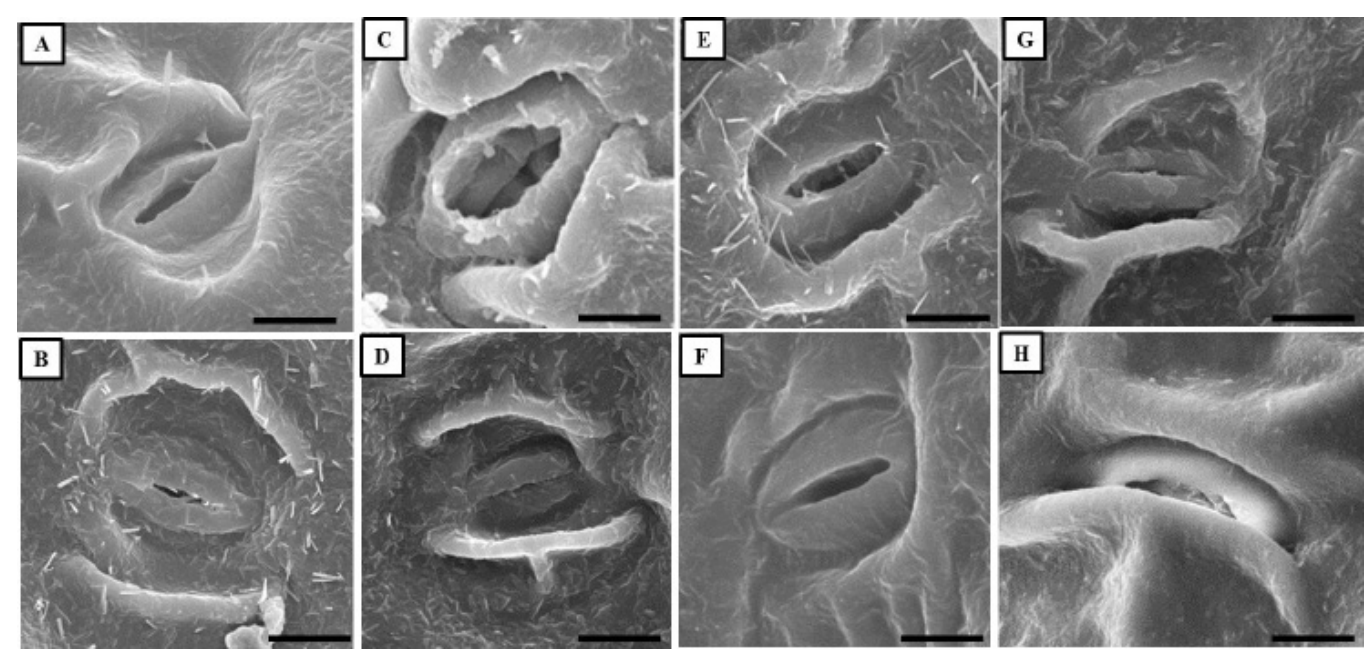

Figure 2. Scanning electron microscopy of abaxial lamina in diploid (UnB 530, 307-1, and Glaz hybrid), triploid (530-5 and 530-19), and chimeric cassava (UnB 530p, Chimera 307-1, and Chimera glaz) showing paracytic stomata. A. UnB 530. B. UnB 530p. C. 530-5. D. 530-19. E. 307-1. F. Chimera 307-1. G. Glaz hybrid. H. Chimera glaz. $\mathrm{Bar}=10 \mu \mathrm{m}$.

\section{Fertility and pollen morphology}

The flowering period of diploid, polyploid, and chimeric plants from March 2009 to April 2013 is graphically represented (Figure 4). From 49 plants within this observation, 30 had some period of flowering. Diploid cultivar UnB 530 flowered for a longer time (30 months), when compared to the others, which ranged 3-20 months. Chimera 307-1 never flowered during 4 years of observation. Chimera glaz flowering period was longer (10) than Glaz hybrid (5). Flowering was predominant in the first semesters of the years.

Regarding ovule maturation and seed production, diploids, polyploids, and chimeras displayed anatropous, bitegumentar, and tricarpellate ovaries, except for Glaz hybrid, which also showed bicarpellate (Figure 5A) and tetracarpellate ovaries (Figure 5B). The ratio ovule/ ovary varied from 2.1 to 2.9 within a total of 867 dissected ovaries and from 1.0 to 2.7 in 162 mature fruits (Figure 6). 


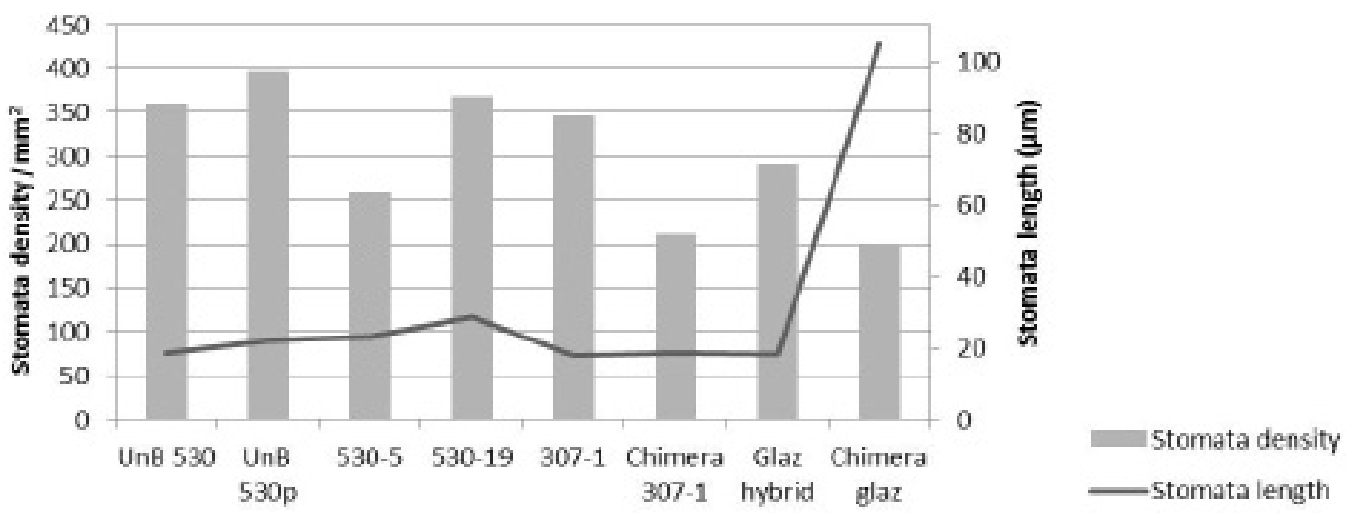

Figure 3. Average of stomata length and density taken within 1369 measurements of diploid (UnB 530, 307-1, and Glaz hybrid), triploid (530-5 and 530-19), and chimeric cassava (UnB 530p, Chimera 307-1, and Chimera glaz).

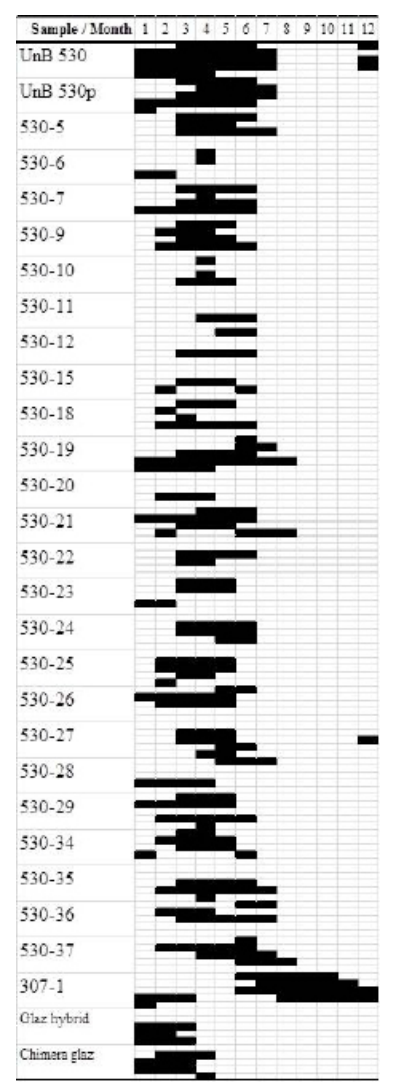

Figure 4. Flowering stages of diploids (UnB 530, 530-18, 307-1, and Glaz hybrid), triploids (530-5 and 53019), tetraploids (530-6, 530-7, 530-9, 530-10, 530-11, 530-12, 530-15, 530-20, 530-21, 530-22, 530-23, 530-24, $530-25,530-26,530-27,530-28,530-29,530-34,530-35,530-36,530-37)$, and chimeric cassava (UnB 530p and Chimera glaz) along 50 months of observation at field. Black marks correspond to flowering periods. Five lines per plant represent each year of observation; numbers at top refer to months. 

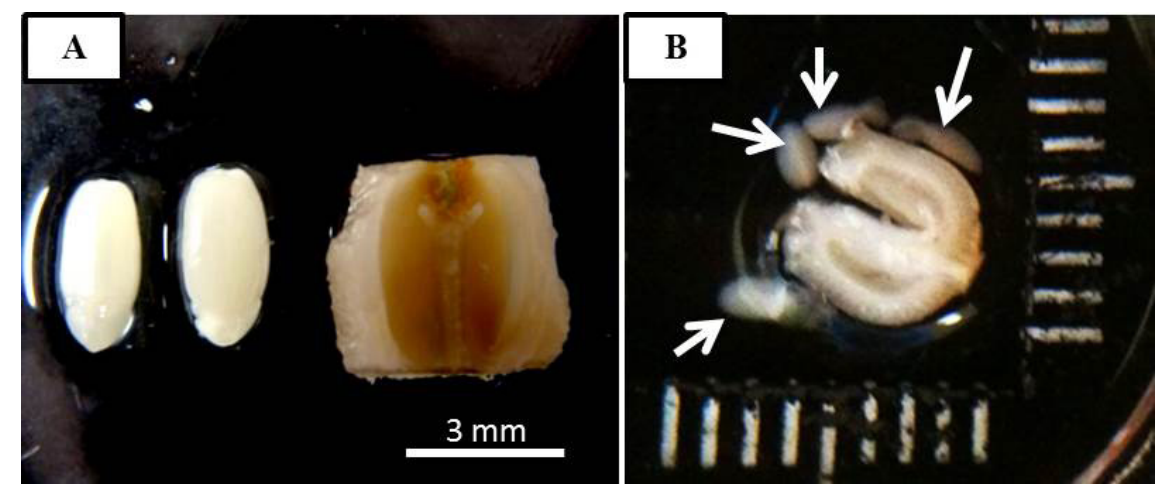

Figure 5. Dissected ovaries of Glaz hybrid with two (A) and four (B) ovules. Bar subunits in $B=1 \mathrm{~mm}$.

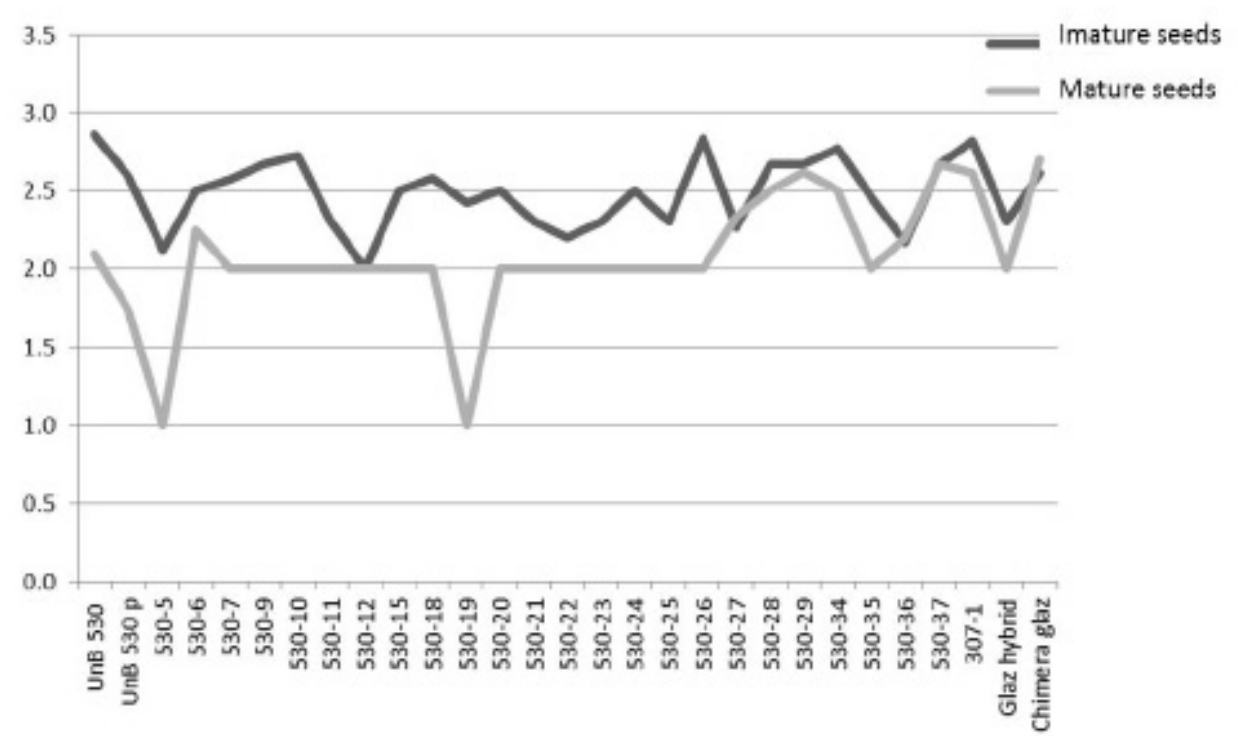

Figure 6. Ratio ovule/ovary (immature seeds) and seed/fruit (mature seeds) for cassava diploid, polyploid, and chimeras. A total of 867 ovaries and 162 fruits were analyzed.

Pollen viability within samples ranged from 34 to $95.7 \%$ for the four cultivars, with progeny and the interspecific hybrid reflecting ploidy level. The Tukey test used in a completely randomized experiment at $\mathrm{P} \leq 0.05$ showed two outermost percentage groups, and an intermediate one. Diploids showed high viability, triploids and hybrid lower values, and tetraploids intermediate. Chimeras UnB 530p and Chimera glaz also showed high pollen viability.

Means of pollen grain diameter of diploid, polyploid, and chimeras ranged from 123.13 to $180.22 \mu \mathrm{m}$. UnB 530, 530-18, 307-1, and Glaz hybrid showed the lowest averages of grain diameters (Figure 7). The biggest ones were 530-1, 530-6, 530-9, 530-13, 530-15, 530-34, 530-35, 530-36, UnB 530p, and Chimera glaz. Enlargement of grain diameter was generally accompanied by an increase in the ploidy level (Figure 8). 


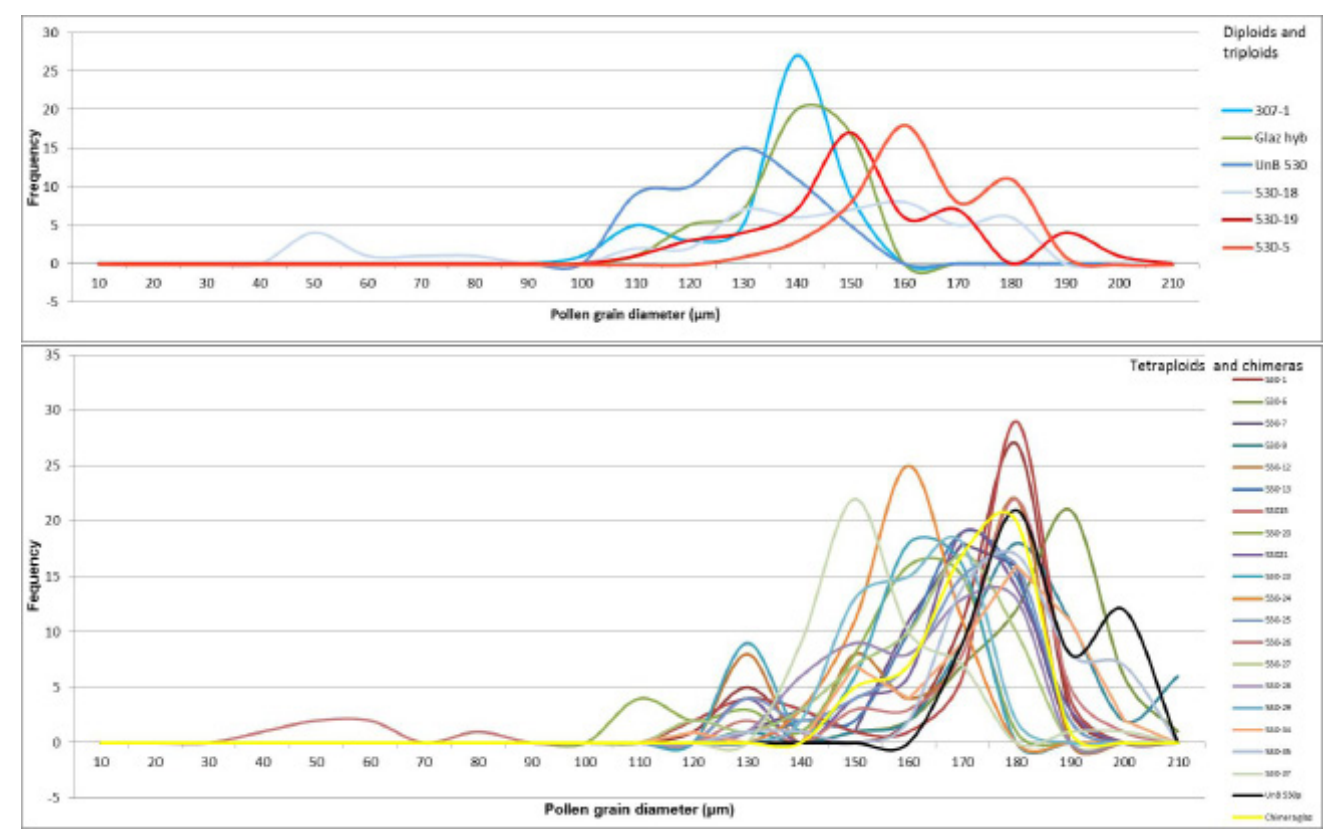

Figure 7. Pollen grain diameters of cassava diploids, triploids, and tetraploids, in addition to the chimeric types UnB 530p and Glaz chimera.

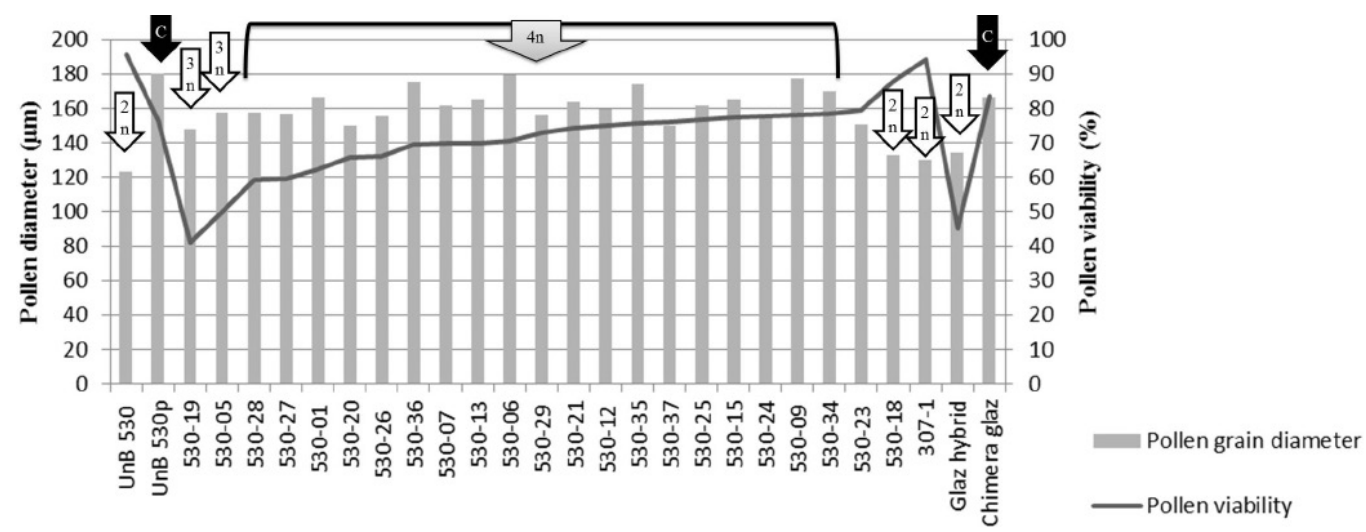

Figure 8. Average of pollen viability percentage of at least 1000 grains per plant of diploids (2n), triploids (3n), tetraploids $(4 n)$, and chimeric cassava $(C)$ and their respective pollen grain diameters from 50 measures per plant.

Tetrad formation (Figure 9) revealed high regularity in diploid cultivars UnB 530 and Chimera glaz, and a significant number of tetrads with micronuclei were seen in UnB 530p, 530-5, 530-19, and 530-36. Cultivar 307-1 and Glaz hybrid exhibited a substantial number of dyads (Table 2). 

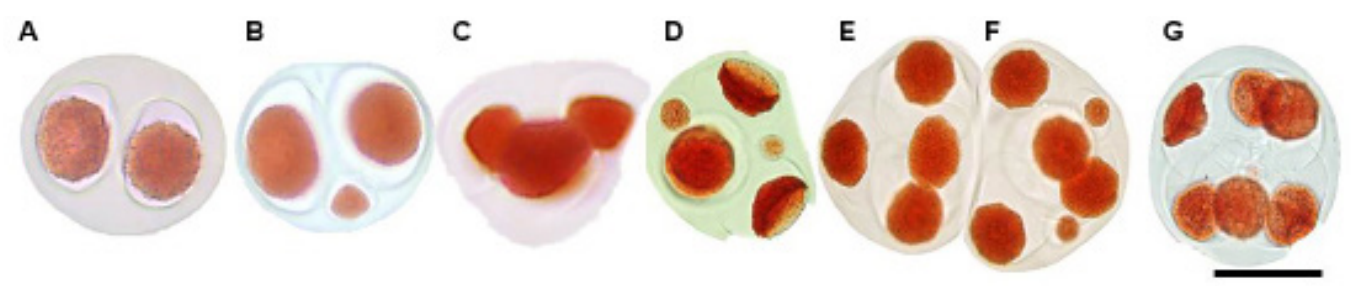

Figure 9. Microspores in diploids (UnB 530, 307-1, and Glaz hybrid), triploids (530-5 and 530-19), tetraploid (530-36), and chimeric samples (UnB 530p, Chimera glaz). A. Dyad; B. dyad with micronucleus; C. triad; D. triad with micronucleus; E. tetrad; F. tetrad with micronuclei; G. polyad. Bar $=25 \mu \mathrm{m}$.

Table 2. Percentage of microspores observed at the end of tetrad stage in diploids (UnB 530, 307-1, and Glaz hybrid), triploids (530-5 and 530-19), tetraploid (530-36) and chimeric samples (UnB 530p and Chimera glaz).

\begin{tabular}{|c|c|c|c|c|c|c|c|c|c|}
\hline \multirow[t]{2}{*}{ Sample } & \multicolumn{2}{|c|}{ Dyads } & \multicolumn{2}{|c|}{ Triads } & \multicolumn{2}{|c|}{ Tetrads } & \multicolumn{2}{|c|}{ Polyads } & \multirow[t]{2}{*}{ Number of microspores } \\
\hline & $\mathrm{N}$ & $\mathrm{MN}$ & $\mathrm{N}$ & $\mathrm{MN}$ & $\mathrm{N}$ & $\mathrm{MN}$ & $\mathrm{N}$ & $\mathrm{MN}$ & \\
\hline UnB 530 & 0.0 & 0.0 & 3.5 & 0.3 & 95.4 & 0.8 & 0.0 & 0.0 & 368 \\
\hline UnB 530p & 0.0 & 0.0 & 1.1 & 0.0 & 51.3 & 47.6 & 0.0 & 0.0 & 649 \\
\hline $530-05$ & 0.4 & 0.4 & 2.0 & 3.5 & 49.8 & 38.9 & 3.9 & 1.1 & 283 \\
\hline $530-19$ & 0.0 & 0.4 & 2.3 & 4.9 & 29.6 & 61.2 & 0.4 & 1.2 & 513 \\
\hline $530-36$ & 0.0 & 0.0 & 2.8 & 0.7 & 56.3 & 40.1 & 0.1 & 0.0 & 684 \\
\hline $307-1$ & 0.0 & 0.0 & 0.0 & 0.0 & 89.4 & 12.6 & 0.0 & 0.0 & 346 \\
\hline Glaz hybrid & 9.5 & 0.0 & 0.0 & 0.0 & 86.3 & 3.7 & 0.4 & 0.0 & 241 \\
\hline Chimera glaz & 0.0 & 0.0 & 1.4 & 0.0 & 97.8 & 0.8 & 0.0 & 0.0 & 356 \\
\hline
\end{tabular}

$\mathrm{N}=$ micronucleus absence. $\mathrm{MN}=$ micronucleus presence.

\section{Chromosome counting and associations}

Mitotic counting and meiotic configuration analyses of diploids, polyploids, and chimeras are illustrated in Figure 10. Meiotic configuration of UnB 530 revealed 36 chromosomes with a configuration of 18 bivalents (Figure 10A) whereas UnB 530p had a mean of 2 univalents, 26 bivalents, 0.4 trivalents, and 3.8 tetravalents, composing 72 chromosomes (Figure 10B). The two progeny of UnB 530p, namely 530-5 (Figure 10C) and 530-19 (Figure 10D), displayed 54 chromosomes, with an average of 2 univalents, 23 bivalents, and 23 trivalents for 530-19. The other individual, 530-36, had a mean of 2.6 univalents, 19.4 bivalents, 0.6 trivalents, and 7.2 tetravalents, totaling 72 chromosomes (Figure 10E). Cultivar 307-1 exhibited $2 \mathrm{n}=36$, in a configuration of 18 bivalents (Figure 10F). In mitotic observations, Chimera 307-1 (Figure 10G), Glaz hybrid (Figure 10H), and its chimera type showed 2n $=36$ (Figure 10I). Chromosome sets of Chimera glaz had an average of 2 univalents, 25 bivalents, and 5 tetravalents, in a total of 72 chromosomes (Figure 10J).

\section{Embryo sac analyses}

Mature ovules of triploid types 530-5, 530-19, and Glaz hybrid revealed higher amounts of aborted sacs, while the other plants had predominantly normal sexual structures (Figure 11). Ovary length for the mature sacs ranged from 4-6 mm. Buds of UnB 530p and Chimera glaz presented two-embryo sacs per ovule (Figure 12) with frequency of 1.3 and 3.3, 
respectively (Table 3). Among the samples analyzed for chimeric type UnB 530p progeny, polyembryos could not be detected.

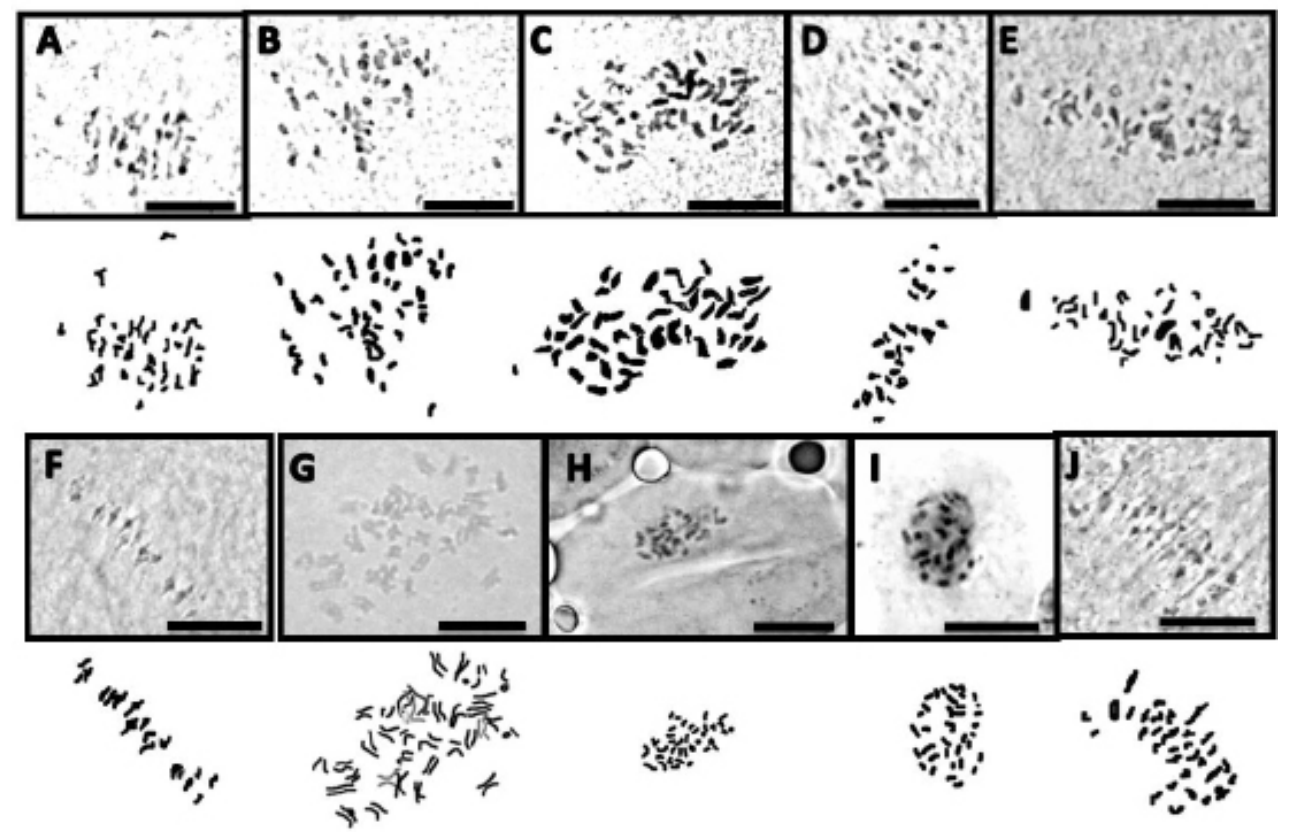

Figure 10. Chromosomes at meiosis (A. B. D. E. J.) and mitosis (C. F. G. H.) in diploids (UnB 530, 307-1, and Glaz hybrid), triploids (530-5 and 530-19), tetraploid (530-36), and chimeric samples (UnB 530p, Chimera glaz). A. UnB 530, 36 chromosomes into 18 bivalents. B. UnB 530p, 72 chromosomes. C. 530-5, 54 chromosomes. D. 53019, 54 chromosomes E. 530-36, 72 chromosomes. F. 307-1, 36 chromosomes. G. Chimera 307-1, 36 chromosomes. H. Glaz hybrid, 36 chromosomes. I. Chimera glaz, 36 chromosomes. J. Chimera glaz, 72 chromosomes. Drawings of cell divisions are represented below each image. Bar $=10 \mu \mathrm{m}$.
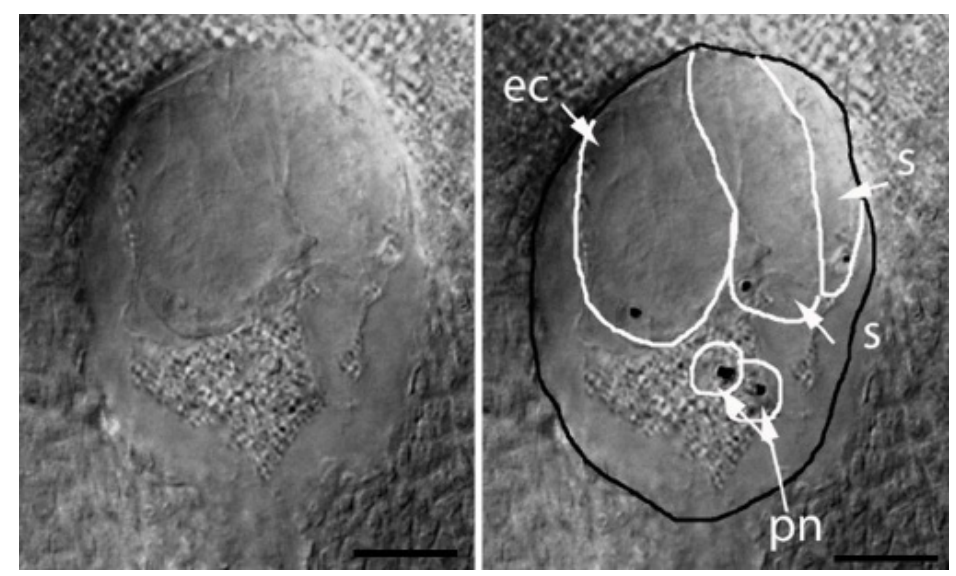

Figure 11. Sexual embryo sac of the cassava diploid cultivar UnB 530 that contains two synergids (s), the egg cell (ec), and two polar nuclei (pn). Bar $=25 \mu \mathrm{m}$. 

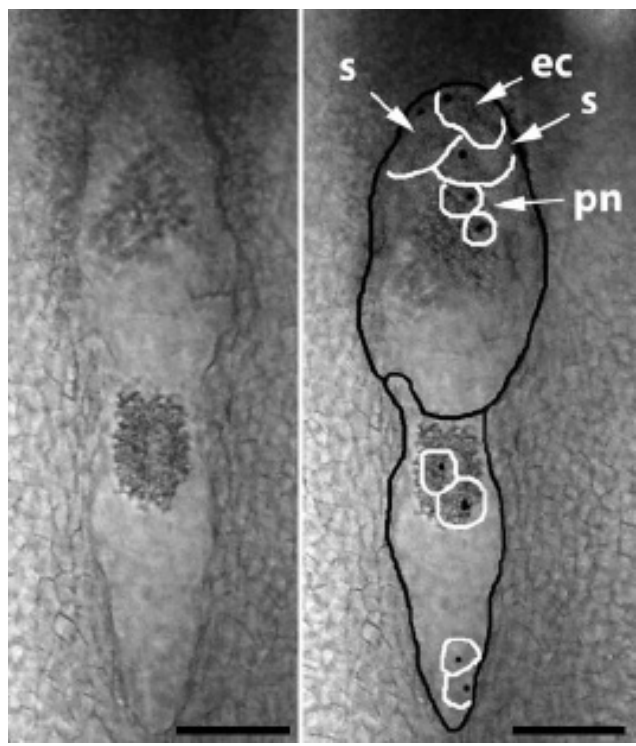

Figure 12. Aposporic embryo sac of Chimera glaz found in ovary of $6 \mathrm{~mm}$. The sexual sac contains synergids (s), the egg cell (ec), and two polar nuclei (pn). Apomictic presents 4 nuclei. Bar $=25 \mu \mathrm{m}$.

Table 3. Number and percentage of sexual, polyembryo, and aborted sacs screened by clearing observations of the ovules in diploids (UnB 530, 530-18, 307-1, and Glaz hybrid), triploids (530-5 and 530-19), tetraploids (530$6,530-7,530-9,530-10,530-11,530-12$, 530-15, 530-20, 530-21, 530-22, 530-23, 530-24, 530-25, 530-26, 530-27, 530-28, 530-29, 530-34, 530-35, 530-36, 530-37), and chimeric cassava (UnB 530p and Chimera glaz).

\begin{tabular}{|c|c|c|c|c|c|c|c|}
\hline \multirow[b]{2}{*}{ Sample } & \multicolumn{2}{|c|}{ Sexual } & \multicolumn{2}{|c|}{ Polyembryo } & \multicolumn{2}{|c|}{ Aborted } & \multirow[t]{2}{*}{ Total } \\
\hline & Number & $\%$ & Number & $\%$ & Number & $\%$ & \\
\hline UnB 530 & 293 & 97.7 & 0 & 0 & 7 & 2.3 & 300 \\
\hline UnB 530p & 274 & 91.3 & 4 & 1.3 & 15 & 5.0 & 300 \\
\hline $530-05$ & 10 & 24.4 & 0 & 0 & 31 & 75.6 & 41 \\
\hline $530-06$ & 29 & 96.7 & 0 & 0 & 1 & 3.3 & 30 \\
\hline $530-07$ & 28 & 93.3 & 0 & 0 & 2 & 6.7 & 30 \\
\hline $530-09$ & 29 & 96.7 & 0 & 0 & 1 & 3.3 & 30 \\
\hline $530-10$ & 27 & 90.0 & 0 & 0 & 3 & 10.0 & 30 \\
\hline $530-11$ & 27 & 90.0 & 0 & 0 & 3 & 10.0 & 30 \\
\hline $530-12$ & 29 & 96.7 & 0 & 0 & 1 & 3.3 & 30 \\
\hline $530-15$ & 29 & 96.7 & 0 & 0 & 1 & 3.3 & 30 \\
\hline $530-18$ & 30 & 100.0 & 0 & 0 & 0 & 0.0 & 30 \\
\hline $530-19$ & 10 & 16.7 & 0 & 0 & 50 & 83.3 & 60 \\
\hline $530-20$ & 27 & 90.0 & 0 & 0 & 3 & 10.0 & 30 \\
\hline $530-21$ & 28 & 93.3 & 0 & 0 & 2 & 6.7 & 30 \\
\hline $530-22$ & 29 & 96.7 & 0 & 0 & 1 & 3.3 & 30 \\
\hline $530-23$ & 29 & 96.7 & 0 & 0 & 1 & 3.3 & 30 \\
\hline $530-24$ & 29 & 96.7 & 0 & 0 & 1 & 3.3 & 30 \\
\hline $530-25$ & 30 & 100.0 & 0 & 0 & 0 & 0.0 & 30 \\
\hline $530-26$ & 29 & 96.7 & 0 & 0 & 1 & 3.3 & 30 \\
\hline $530-27$ & 27 & 90.0 & 0 & 0 & 3 & 10.0 & 30 \\
\hline $530-28$ & 26 & 86.7 & 0 & 0 & 4 & 13.3 & 30 \\
\hline $530-29$ & 30 & 100.0 & 0 & 0 & 0 & 0.0 & 30 \\
\hline $530-34$ & 30 & 100.0 & 0 & 0 & 0 & 0.0 & 30 \\
\hline $530-35$ & 28 & 93.3 & 0 & 0 & 2 & 6.7 & 30 \\
\hline $530-36$ & 28 & 93.3 & 0 & 0 & 2 & 6.7 & 30 \\
\hline $530-37$ & 29 & 96.7 & 0 & 0 & 1 & 3.3 & 30 \\
\hline $307-1$ & 60 & 90.9 & 0 & 0 & 6 & 9.1 & 66 \\
\hline Glaz hybrid & 5 & 25.0 & 0 & 0 & 5 & 25.0 & 20 \\
\hline Chimera glaz & 54 & 90.0 & 2 & 3.3 & 4 & 6.7 & 60 \\
\hline
\end{tabular}




\section{Root production}

Roots (Figure 13) of cassava cultivars of diploid type UnB 530 and its chimera UnB 530p, summed to triploid (530-19) type grown from this chimera progeny, and of 307-1 and its chimera formed edible structures varying slightly in number, but the most exceptional performance was the productivity of the chimeric type, which exhibited twice the weight (Table 4).

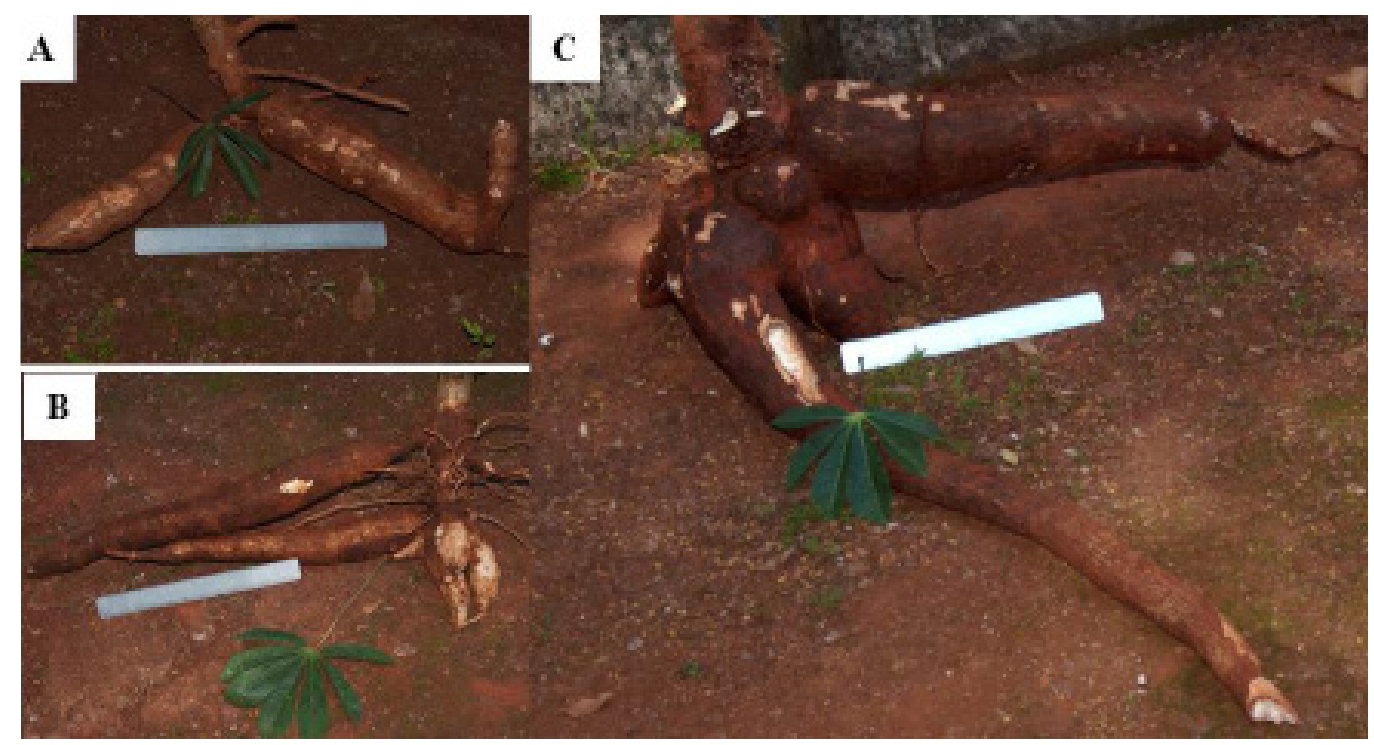

Figure 13. Edible roots of A. UnB 530 (diploid); B. 530-19 (triploid); and C. UnB 530p (chimera).

\begin{tabular}{lcc} 
Table 4. Root number and weight of cassava cultivars. & \\
\hline Sample & Number of roots & Weight $(\mathrm{kg})$ \\
\hline UnB 530 & 2 & 2.5 \\
UnB 530p & 4 & 12 \\
$530-19$ & 6 & 3.5 \\
$530-36$ & 5 & 2.8 \\
\hline
\end{tabular}

Diploid (UnB 530), triploid (530-19), tetraploid (530-36), and chimera (UnB 530p).

\section{DISCUSSION}

Cytochimera studies are usually related to polyploidization treatments with colchicine (Dermen and Bain, 1944). More recently, histogenic identification of colchicine-treated plants in Hemerocallis (Podwyszyńska et al., 2008), Vaccinium (Chavez and Lyrene, 2009), and Magnolia (Parris et al., 2010) led to morpho-anatomical characterization of apical shoots and derivative organs. Despite these investigations dealt with several species from botanical aspects, their function for breeding purposes needs to be elucidated.

Colchicine application on lateral buds of cassava cultivars and interspecific hybrid in this study, with subsequent vegetative propagation, generated cytochimeras. They were 
proven to have chimerical compositions by anatomical, morphological, and cytogenetic criteria. Regarding apical shoot anatomy, there was significantly marked increase in cell size in L1 and L2 of UnB 530p, Chimera 307-1, and Chimera glaz, especially in Chimera glaz, in which variation in values was greater. Therefore, we could identify chimeras among our plants, in which L1 and L2 contained polyploidized cells. Cell size in apical shoot has been taken as an indicator of polyploidized layers also in other species (Laufs et al., 1998; Burge et al., 2002).

Stomatal size also proved to be a useful indicator in initial screening of ploidy levels at L1 of our cytochimeric cassava plants. This feature was notably increased in UnB 530p, Chimera 307-1, and Chimera glaz, confirming their polyploid configuration, such as in triploids 530-5 and 530-19. Direct relationship of stomatal size and increase in ploidy was also reported for Citrus (Yahata et al., 2005) and Acacia (Harbard et al., 2012). Stomatal density decreased in cytochimeras of 307-1 and Glaz hybrid. A similar result was observed for Platanus (Liu et al., 2007) and Spatiphyllum (Van Laere et al., 2011). Unlike stomatal length, stomatal density shows more restrictions in use as a marker for ploidy determination, as it varies even between individuals from different ploidy levels within the same species (Rupp et al., 2010). Therefore, stomatal density was not significant for L1 ploidy detection in UnB 530, UnB 530p, and its progeny.

Multiple chromosome sets generated by L2 polyploidization influenced all meiotic pathway in cytochimeras and total polyploids in this study. Indeed, gamete formation is generally attributed to the L2 cell layer (Fletcher, 2002). Diploid cultivars, which were UnB 530 and 307-1, produced cytochimeras that showed similar behavior; UnB 530p had a general decrease in fertility, pollen viability, and tetrad regularity, while Chimera 307-1 had complete absence of flowering.

On the other hand, polyploid composition of Chimera glaz had restored plant fertility, showing increases in the above parameters. Plant sterility is related to hybrid incompatibility in diploid types (Benavente et al., 2008), which seems to be the case of Glaz hybrid. Multivalent associations in polyploids are involved in low fertility (Grandont et al., 2013), a fact observed in UnB 530p and polyploids 530-19 and 530-36. Complete sterility has been observed in some plant chimeras (Wang et al., 2010). This may be attributed to epigenetic regulation, in which several aberrant genetic interactions (Rodrigues and Koltunow, 2005) triggered by an additive effect of polyploidy caused absence of flowering in Chimera 307-1.

While pollen viability allowed the recognition of diploids, triploids, and polyploids among our plants, pollen grain size characterized ploidy levels as well. In diploid 530-18, and other total triploids and tetraploids, which were established from seeds, pollen grain viability, and size offer a quick and reliable way to detect L2 polyploidization.

Chromosome counting and configuration from male buds and root tips directly indicated cytochimeric and total polyploid composition at L2 and L3 layers. From these lines of evidence, total diploids (UnB 530, 530-18, 307-1, and Glaz hybrid), total triploids (530-5 and 530-19), total tetraploids (530-6, 530-7, 530-9, 530-10, 530-11, 530-12, 530-15, 530-20, 530$21,53-22,530-23,530-24,530-25,530-26,530-27,530-28,530-29,530-34,530-35,530-36$, 530-37), and cytochimeras 4n-4n-2n (UnB 530p, Chimera 307-1, and Chimera glaz) could be identified. Cultivars UnB 530 and 307-1 showed a regular number and configuration of diploid plants, in accordance with their also regular tetrad formation. On the other hand, UnB 530p chimeric constitution led to the occurrence of multivalents besides decrease in tetrad formation regularity. One of the most interesting results was the high frequency of dyads in Glaz hybrid and tetrads with micronuclei. Its cytochimera, seasonable, had higher tetrad regularity due to chromosome pairing (Comai, 2005). 
Meiotic irregularities observed in total polyploids and chimeras are potentially related to aborted embryo sacs in triploids and Glaz hybrid. Polyembryo sacs detected in polyploidized samples of UnB 530p and Chimera glaz were probably due to genetic duplication of L2. Although female gamete formation has been reported for L2 (Burge et al., 2002), there is evidence that L1 may be involved in apomictic embryo sac formation, besides L2 itself (Koltunow and Grossniklaus, 2003). Ploidy relationship and low frequencies of polyembryo sacs in cassava have been reported (Nassar et al., 2010; Freitas and Nassar, 2013).

In spite of some reports attributed to polyploidy, an increase in polyembryo frequency, e.g., apomixis, was not observed in the progeny of the chimeric cassava UnB 530p. This may suggest recessive genes for control of this character in Manihot (Nassar, 2002; Nassar et al., 2009).

Mitotic results revealed the L3 diploid nature of Chimera 307-1 and Chimera glaz. Since root derives from the inner layer, we traced this layer by anatomical examination of apical shoots of UnB 530p and confirmed its chimeric constitution because of having a diploid L3.

Root production of chimeric cassava plants was greater in size compared to total triploid or tetraploid. This may be attributed to an epigenetic effect in cytochimeras (Szymkowiak and Sussex, 1996). Intercellular morphogenetic interactions and cell displacement might have occurred in our cytochimeric plant, supporting the hypothesis of epigenetic and molecular influences in genetically different cells. Coexistence of different ploidy levels of L1, L2, and L3 in chimeric cassava plants seems to have created a favorable environment for increasing root production. Epigenetic interactions also led to the absence of flowering in Chimera 307-1, occurrence of polyembryo sacs in UnB 530p and Chimera glaz, and this extraordinary increase in root production in chimera plants.

\section{ACKNOWLEDGMENTS}

Research supported by Coordenação de Aperfeiçoamento de Pessoal de Nível Superior (CAPES, for the PhD student D.Y. Hashimoto-Freitas) and Conselho Nacional de Desenvolvimento Científico e Tecnológico (CNPq, for the senior author N.M.A. Nassar). The above mentioned Living Collection of Manihot was established at Universidade de Brasília in the 1970s, with support from the International Development Research Centre (IDRC), Canada, to which we are grateful.

\section{REFERENCES}

Benavente E, Cifuentes M, Dusautoir JC and David J (2008). The use of cytogenetic tools for studies in the crop-to-wild gene transfer scenario. Cytogenet. Genome Res. 120: 384-395.

Burge GK, Morgan ER and Seelye JF (2002). Opportunities for synthetic plant chimeric breeding: Past and future. Plant Cell Tiss. Org. 70: 13-21.

Ceballos H, Iglesias CA, Perez JC and Dixon AG (2004). Cassava breeding: opportunities and challenges. Plant Mol. Biol. 56: 503-516.

Chavez DJ and Lyrene PM (2009). Production and identification of colchicine-derived tetraploid Vaccinium darrowii and its use in breeding. J. A. Soc. Hortic. Sci. 134: 356-363.

Comai L (2005). The advantages and disadvantages of being polyploid. Nat. Rev. Genet. 6: 836-846.

De Carvalho R and Guerra M (2002). Cytogenetics of Manihot esculenta Crantz (cassava) and eight related species. Hereditas 136: 159-168.

Dermen H and Bain HF (1944). A general cytohistological study of colchicine polyploidy in cranberry. Am. J. Bot. 31: 451-563.

FAO (Food and Agriculture Organization of the United Nations) (2013). Cassava: A Guide to Sustainable Production 
Intensification. Food and Agriculture Organization of the United Nations, Rome.

Fletcher JC (2002). Shoot and floral meristem maintenance in Arabidopsis. Annu. Rev. Plant Biol. 53: 45-66.

Freitas DY and Nassar NM (2013). Apomixis in cassava: advances and challenges. Genet. Mol. Res. 12: 988-994.

Gomes PT and Nassar NM (2013). Cassava interspecific hybrids with increased protein content and improved amino acid profiles. Genet. Mol. Res. 12: 1214-1222.

Grandont L, Jenczewski E and Lloyd A (2013). Meiosis and its deviations in polyploid plants. Cytogenet. Genome Res. 140: 171-184.

Hahn SK, Bai K and Vand Asiedu R (1990). Tetraploids, triploids, and 2n pollen from diploid interspecific crosses with cassava. Theor. Appl. Genet. 79: 433-439.

Harbard JL, Griffin AR, Foster S, Booker C et al. (2012). Production of colchicine-induced autotetraploids as a basis for sterility breeding in Acacia mangium Willd. Forestry 85: 427-436.

Koltunow AM and Grossniklaus U (2003). Apomixis: a developmental perspective. Annu. Rev. Plant Biol. 54: 547-574.

Kraus JE and Arduin M (1997). Manual Básico de Métodos em Morfologia Vegetal. EDUR, Seropédica.

Laufs P, Grandjean O, Jonak C, Kieu K, et al. (1998). Cellular parameters of the shoot apical meristem in Arabidopsis. Plant Cell 10: 1375-1390.

Liu G, Li Z and Bao M (2007). Colchicine-induced chromosome doubling in Platanus acerifolia and its effect on plant morphology. Euphytica 157: 145-154.

Marcotrigiano M and Bernatzky R (1995). Arrangement of cell layers in the shoot apical meristems of periclinal chimeras influences cell fate. Plant J. 7: 193-202.

Nassar NMA (1978). Chromosome number and meiotic behaviour of some wild Manihot species native to Central Brazil. Braz. J. Genet. 1: 51-57.

Nassar NMA (2002). Apomixis and Cassava. Genet. Mol. Res. 1: 147-152.

Nassar NMA (2003). Fertility and chimera induction in cassava interspecific hybrids. Gene Conserve 2: 117-123.

Nassar NMA and Ortiz R (2008). Cassava genetic resources: manipulation for crop improvement. Plant Breed. Rev. 31: 247-275.

Nassar NM, Gomes PT, Chaib AM, Bomfim NN, et al. (2009). Cytogenetic and molecular analysis of an apomictic cassava hybrid and its progeny. Genet. Mol. Res. 8: 1323-1330.

Nassar NM, Hashimoto DY and Ribeiro DG (2010). Genetic, embryonic and anatomical study of an interspecific cassava hybrid. Genet. Mol. Res. 9: 532-538.

Nassar NMA, Hashimoto-Freitas DY, Mendoza MJ, Rodrigues E, et al. (2012). Some interesting cassava cultivars: 11UnB 530p. Gene Conserve 11: 7-10.

Paiva JGA, Fank-de-Carvalho SM, Magalhães MP and Graciano-Ribeiro D (2006). Verniz vitral 500: uma alternativa de meio de montagem economicamente viável. Acta Bot. Bras. 20: 257-264.

Parris JK, Ranney TG, Knap HT and Baird WV (2010). Ploidy levels, relative genome sizes, and base pair composition in Magnolia. J. Amer. Soc. Hort. Sci. 135: 533-547.

Podwyszyńska M, Gabryszewska E, Sochacki D and Jasinski A (2008). Histogenic identification by cytological analysis of colchicine-induced polyploids of Hemerocallis. Acta Hortic. 886: 245-249.

Rodrigues JCM and Koltunow AMG (2005). Epigenetic aspects of sexual and asexual seed development. Acta Biol. Cracov. Bot. 47: 37-49.

Rupp B, Samuel R, Russell A, Temsch EM, et al. (2010). Genome size in Polystachya (Orchidaceae) and its relationships to epidermal characters. Bot. J. Linn. Soc. 163: 223-233.

Sreekumari MT, Abraham K and Nair SG (2000). Triploidy Breeding in Cassava. Central Tuber Crops Research Institute (Indian Council of Agricultural Research), Thiruvananthapuram.

Szymkowiak EJ and Sussex IM (1996). What chimeras can tell us about plant development. Annu. Rev. Plant Physiol. Plant Mol. Biol. 47: 351-376.

Van Laere K, França SC, Vansteenkiste H, Van Huylenbroeck J, et al. (2011). Influence of ploidy level on morphology, growth and drought susceptibility in Spathiphyllum wallisii. Acta Physiol. Plant 33: 1149-1156.

Wang Y, Cheng Q, Zhu XY and Chen LP (2010). Studies on reproductive characteristics of an interspecific chimera between Brassica juncea and Brassica oleracea. Plant Cell Tiss. Org. 104: 209-215.

Yahata M, Kunitake H, Yabuya T and Yamashita K, et al. (2005). Production of a doubled haploid from a haploid pummelo using colchicine treatment of axillary shoot buds. J. A. Soc. Hortic. Sci. 130: 899-903.

Young BA, Sherwood RT and Bashaw E (1979). Cleared-pistil and thick-sectioning techniques for detecting aposporous apomixis in grasses. Can. J. Bot. 57: 1668-1672.

Zhu XY, Zhao M, Ma S, Ge YM, et al. (2007). Induction and origin of adventitious shoots from chimeras of Brassica juncea and Brassica oleracea. Plant Cell Rep. 26: 1727-1732. 